\title{
New verticilides, inhibitors of acyl-CoA:cholesterol acyltransferase, produced by Verticillium sp. FKI-2679
}

\author{
Taichi Ohshiro ${ }^{1}$, Daisuke Matsuda ${ }^{1}$, Takeuchi Kazuhiro ${ }^{1}$, Ryuji Uchida ${ }^{1}$, Kenichi Nonaka ${ }^{2}$, Rokuro Masuma ${ }^{2}$ \\ and Hiroshi Tomoda ${ }^{1}$ \\ Verticillium sp. FKI-2679, a soil isolate, was found to produce inhibitors of acyl-CoA:cholesterol acyltransferase (ACAT) in \\ a cell-based assay using ACAT1- and ACAT2-expressing CHO cells. Three new compounds, verticilides A2, A3 and B1, were \\ isolated along with a known compound, verticilide $A 1$, from the fermentation broth of the fungus by solvent extraction, ODS \\ column chromatography, silica gel column chromatography and preparative HPLC. Structure elucidation showed that these \\ compounds were new cyclic depsipeptide. Verticilides A1, A2, A3 and B1 showed a degree of selectivity towards ACAT2, \\ with $\mathrm{IC}_{50}$ s 8.5-11-fold more potent than observed against ACAT1.
}

The Journal of Antibiotics (2012) 65, 255-262; doi:10.1038/ja.2012.12; published online 14 March 2012

Keywords: acyl-CoA:cholesterol acyltransferase; cyclodepsipeptide; fungal metabolite; inhibitor; verticilide; Verticillium

\section{INTRODUCTION}

Acyl-CoA:cholesterol acyltransferase (ACAT, EC 2.3.1.26), an endoplasmic reticulum (ER) membrane protein, is responsible for many functions in the body. ACAT has been postulated as a target for modulation by a new type of anti-atherosclerotic agent. ${ }^{1}$ Many pharmaceutical laboratories have developed synthetic ACAT inhibitors; however, none could be successfully developed to date because of either side effects or low in vivo efficacy. ${ }^{2,3}$ Recent molecular biological studies have revealed the existence in mammals of two different ACAT isozymes, ACAT1 and ACAT2. ${ }^{4-7}$ ACAT1 is ubiquitously expressed in tissues and cells, whereas ACAT2 is expressed predominantly in the liver (hepatocytes) and intestine. ${ }^{8}$ ACAT1-deficient $\left(\right.$ Acat $\left.^{-l-}\right)$ mice are viable and fertile, and ACAT activity is present in the liver and intestine but completely absent in the adrenal cortex and peritoneal macrophages. ${ }^{9-11}$ However, in addition to having dry eye syndrome, ${ }^{9}$ Acat $1^{-l-}$ mice lacking apolipoprotein $\mathrm{E}$ or the low-density lipoprotein receptor, as atherogenic mouse models, are susceptible to atherosclerosis and had extensive cutaneous xanthomatosis with loss of hair. ${ }^{10,11}$ Free cholesterol content was significantly increased in their skin. In contrast, ACAT activity is completely absent in the liver and intestine of ACAT2-deficient $\left(\right.$ Acat2 $\left.^{-l-}\right)$ mice and these mice are completely resistant to diet-induced hypercholesterolemia and cholesterol gallstone formation. ${ }^{12,13}$ Therefore, it is important to determine the selectivity of inhibitors toward the two ACAT isozymes for their development as new anti-atherosclerotic agents. However, only a few studies have been reported so far. ${ }^{14-16}$

Before the discovery of the two different ACAT isozymes, our group had focused on the discovery of ACAT inhibitors of microbial origin in an enzyme assay using rat liver microsomes. ${ }^{17}$ Since ACAT isozymes discovery, we refocused on the discovery of ACAT2-selective inhibitors and improved the assay system ${ }^{15}$ by utilizing two cell lines, Chinese hamster ovary $(\mathrm{CHO})$ cells expressing African green monkey ACAT1 (ACAT1-CHO cells) and ACAT2 (ACAT2-CHO cells). ${ }^{14}$ During our screening programme, ${ }^{18,19}$ four structurally related compounds were isolated from the culture broth of a fungal strain FKI-2679 as inhibitors of both ACAT isozymes in cell-based assays. One was identified as verticilide (verticilide A1 in this study), which had previously been reported to have insecticidal activity, ${ }^{20,21}$ but the others were new compounds, named verticilides A2, A3 and B1 (Figure 1). They are members of the cyclodepsipeptide family such as beauveriolides, ${ }^{22-24}$ beauvericin, ${ }^{25}$ enniatin ${ }^{26}$ and bassianolide. ${ }^{27}$ In this study, the taxonomy of the producing strain, fermentation, isolation, structure elucidation and biological properties of verticilides are described.

\section{RESULTS AND DISCUSSION}

Taxonomy of strain FKI-2679

Colonies on potato dextrose agar (PDA) after 7 days at $25^{\circ} \mathrm{C}$ (Figure 2a) were $57-60 \mathrm{~mm}$ in diameter, floccose to velvety and white (hue number; a). The reverse side was yellowish-gray (hue number; 2ca). Colonies on malt extract agar (MEA) after 7 days at $25^{\circ} \mathrm{C}$ (Figure 2b) were $36-38 \mathrm{~mm}$ in diameter, floccose to velvety and white (hue number; a). The reverse side was yellowish-gray (hue number; 2ca). Colonies on Miura's medium (LCA) after 7 days at $25^{\circ} \mathrm{C}$ (Figure 2c) were $44-45 \mathrm{~mm}$ in diameter, floccose to velvety and white (hue number; a). The reverse side was white (hue number; a).

${ }^{1}$ Graduate School of Pharmaceutical Sciences, Kitasato University, 5-9-1 Shirokane, Minato-ku, Tokyo, Japan and ${ }^{2}$ Kitasato Institute for Life Sciences, Kitasato University, 5-9-1 Shirokane, Minato-ku, Tokyo, Japan

Correspondence: Professor H Tomoda, Graduate School of Pharmaceutical Sciences, Kitasato University, 5-9-1 Shirokane, Minato-ku, Tokyo 108-8641, Japan.

E-mail: tomodah@pharm.kitasato-u.ac.jp

Received 5 November 2011; revised 24 January 2012; accepted 2 February 2012; published online 14 March 2012 


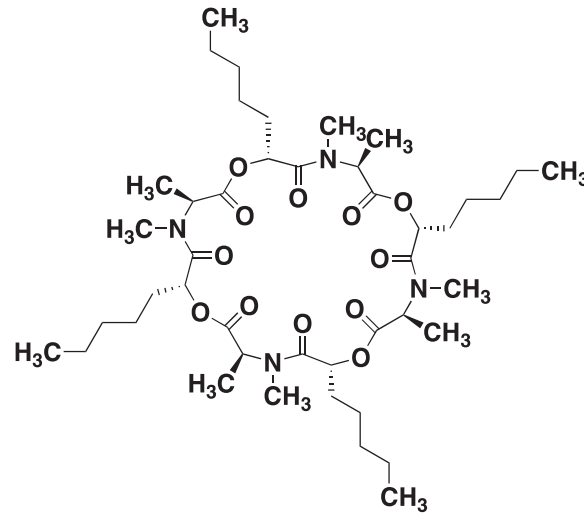

Verticilide A1

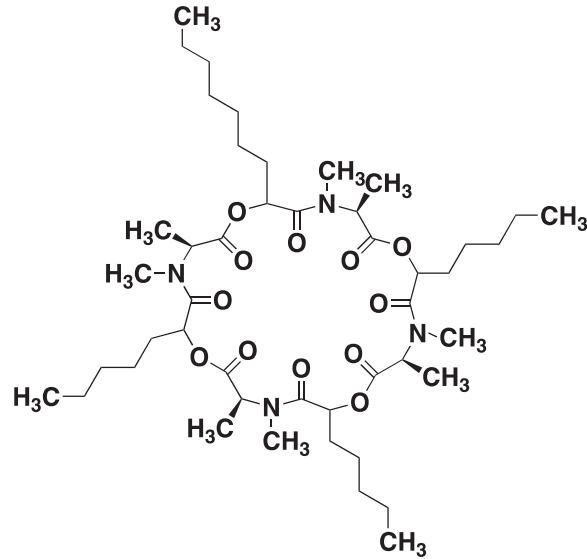

Verticilide A3

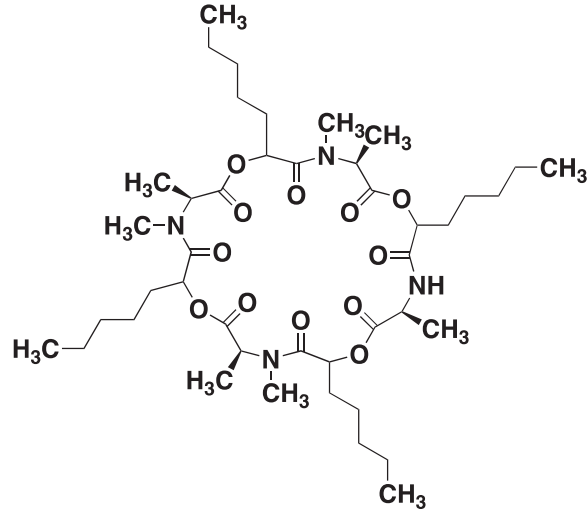

Verticilide A2<smiles>CCCCCCC(OC(=O)C(C)N(C)C(=O)C(C)C)C(=O)N(C)C(C)C(=O)OC(CCCCCC)C(=O)N(C)C(C)C(=O)OC(CCCCC)C(=O)OC(C)C</smiles>

Verticilide B1

Figure 1 Structures of verticilides $A 1, A 2, A 3$ and $B 1$.

Colonies on potato carrot agar (PCA) after 7 days at $25^{\circ} \mathrm{C}$ (Figure $2 \mathrm{~d}$ ) were $49-50 \mathrm{~mm}$ in diameter, floccose to velvety and white (hue number; a). The reverse side was yellowish-white (hue number; a). Colonies on PDA at 5 and $37^{\circ} \mathrm{C}$ were not observed. Conidiophores were from basal hyphae, rarely branching. The phialides were slender, $22.5-47.5 \times 1.5-2.5 \mu \mathrm{m}$. Conidia were slimy globose heads, subglobose to cylidrical $(2.0-4.5 \mu \mathrm{m})$. From these morphological characteristics, ${ }^{28}$ the producing strain FKI-2679 was considered to belong to the genus Verticillium. From the taxonomic study, strain FKI-2679 appeared very similar to strain FKI-1033, which was previously reported as a producer of the insecticidal verticilide A1. ${ }^{20,21}$ Though they may be classified to the same species, strain FKI-2679 was isolated from a soil sample collected from Okinawa, Japan, whereas strain FKI-1033 was isolated from a sample collected from Kagoshima, Japan. ${ }^{20,21}$ Furthermore, their secondary metabolites and productivity were different.

\section{Isolation}

To the 15-day-old whole broth (101) 101 of ethanol was added. After the mixture was filtered and concentrated to remove ethanol, the residual aqueous solution was extracted with ethyl acetate. The extracts were dried over $\mathrm{Na}_{2} \mathrm{SO}_{4}$ and concentrated in vacuo to dryness to yield a brown oily material $(4.4 \mathrm{~g})$. The material was dissolved in hexane-ethyl acetate $(20: 1, \mathrm{v} / \mathrm{v})$, applied to a silica gel column $(130 \mathrm{~g})$ and eluted stepwise with 20:1, 10:1, 5:1, 3:1 and 1:1 (v/v) of hexaneethyl acetate and 100:0, 100:1, 50:1, 25:1, 10:1, 1:1 and 0:100 (v/v) of $\mathrm{CHCl}_{3}-\mathrm{MeOH}$ (11 for each solvent). Active fractions from a 1:1 solvent of hexane-ethyl acetate-containing verticilides were concentrated in vacuo to dryness to give a red-brown oily material $(170 \mathrm{mg})$. The material was finally purified by preparative HPLC (column: PEGASIL ODS (Senshu Scientific Co. Ltd., Tokyo, Japan), $20 \times 250 \mathrm{~mm}$; the solvent is presumably $87 \%$ aqueous $\mathrm{CH}_{3} \mathrm{CN}$; detection, $\mathrm{UV}$ at $210 \mathrm{~nm}$; flow rate, $8.0 \mathrm{ml} \mathrm{min}^{-1}$ ). Under these conditions, verticilides $\mathrm{B} 1, \mathrm{~A} 1, \mathrm{~A} 2$ and $\mathrm{A} 3$ were eluted as peaks with retention times of 19.5, 27.8, 33.1 and $42.8 \mathrm{~min}$, respectively (Figure 3 ). The fractions were concentrated in vacuo to dryness to give pure verticilides A1 (54 mg), A2 (0.91 mg), A3 (0.80 mg) and B1 (4.2 mg) as colorless oils.

\section{Structural elucidation of verticilides A2, A3 and B1}

Physico-chemical properties of verticilides A2, A3 and B1. The physicochemical properties of verticilides A2, A3 and B1 are summarized in Table 1. They had similar UV spectra with end absorption maxima at $202 \mathrm{~nm}$. The IR absorption at $1650-1754 \mathrm{~cm}^{-1}$ suggested the presence of carbonyl groups in their structures. These data were similar to those of verticilide $\mathrm{A1},{ }^{20,21}$ indicating that they were also likely to be cyclodepsipeptides. 

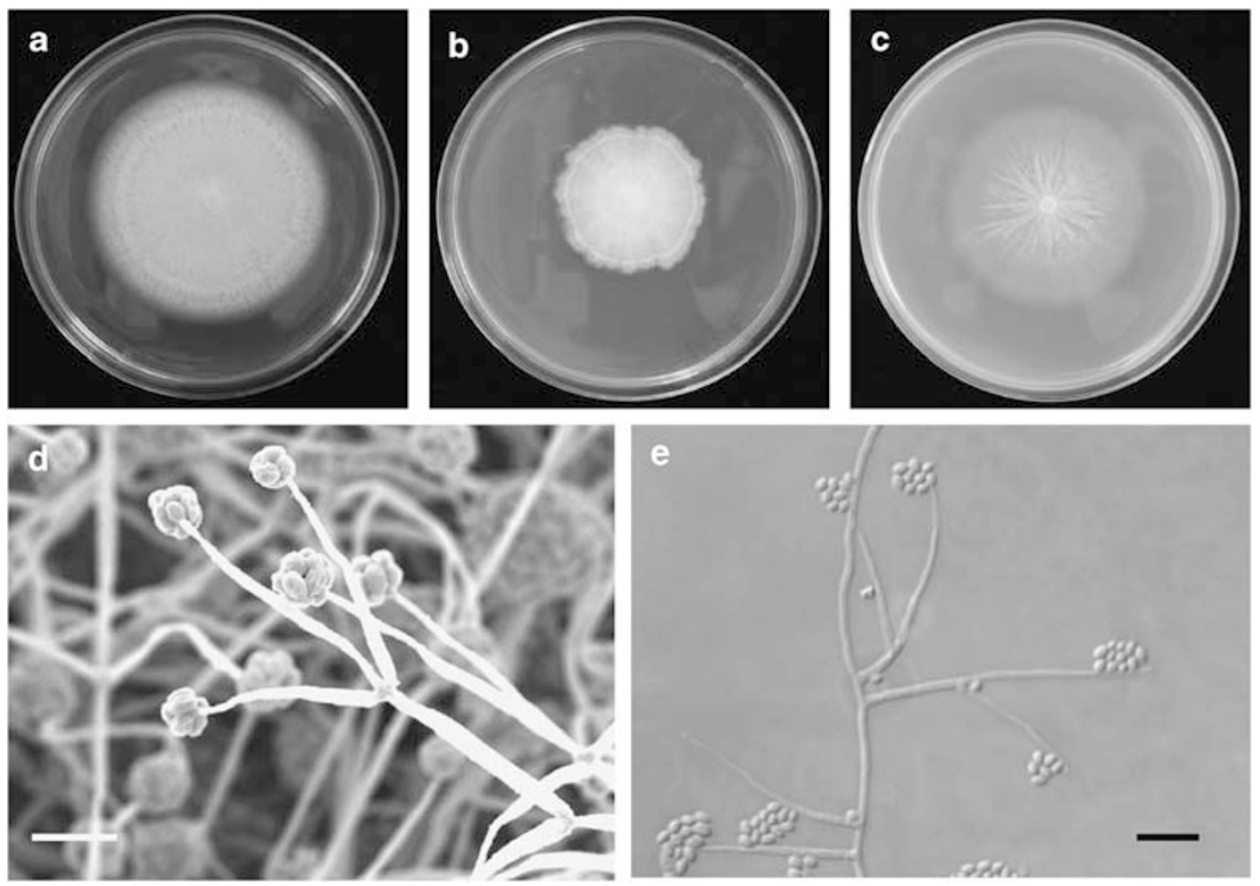

Figure 2 Morphological characteristics of verticilide-producing fungal strain FKI-2679. (a) Micrography of colonies grown on PDA after 7 days. (b) Micrograph of colonies grown on MEA after 7 days. (c) Micrograph colonies grown on PCA after 7 days. (d) Scanning electron micrograph of conidiophores grown on PDA. Scale bar, $10 \mu \mathrm{m}$. (e) Micrograph of synnemata grown on PDA. Scale bar, $10 \mathrm{~mm}$. A full color version of this figure is available at The Journal of Antibiotics online.

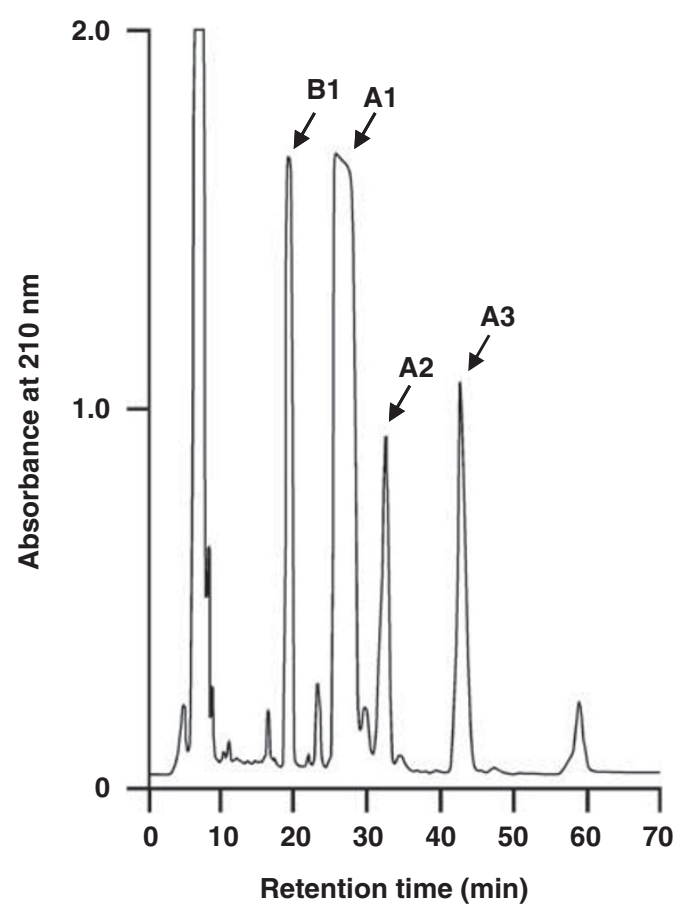

Figure 3 Chromatographic profile of verticilide purification by preparative HPLC. Column, PEGASIL ODS $(20 \times 250 \mathrm{~mm})$; solvent $87 \%$ aqueous acetonitrile; detection, $\mathrm{UV}$ at $210 \mathrm{~nm}$; flow rate, $8.0 \mathrm{ml} \mathrm{min}^{-1}$.

Amino-acid analysis of verticilides $A 2, A 3$ and B1. The acid hydrolysates of verticilides $\mathrm{A} 2, \mathrm{~A} 3$ and $\mathrm{B} 1\left(6 \mathrm{~N} \mathrm{HCl}\right.$ at $110^{\circ} \mathrm{C}$ for $\left.24 \mathrm{~h}\right)$ were separated by chiral TLC, and the TLC plates were sprayed with ninhydrin to detect the presence of amino acids by their color reactions. Only the presence of $N$-methyl-L-alanine was detected for verticilides $\mathrm{B} 1$ and $\mathrm{A} 3$, whereas both $N$-methyl-L-alanine and L-alanine were found for verticilde A2.

Structure of verticilide A2. The molecular formula of verticilide A2 was determined to be $\mathrm{C}_{43} \mathrm{H}_{74} \mathrm{~N}_{4} \mathrm{O}_{12}$ on the basis of HR-FAB-MS measurement $\left(\mathrm{m} / \mathrm{z}\right.$, found 839.5372, calcd 839.5381 for $\mathrm{C}_{43} \mathrm{H}_{75} \mathrm{~N}_{4} \mathrm{O}_{12}$ $\left.[\mathrm{M}+\mathrm{H}]^{+)}\right)$, indicating that it was smaller than verticilide $\mathrm{Al}$ by one carbon atom and two protons. The ${ }^{1} \mathrm{H}$ and ${ }^{13} \mathrm{C}$ NMR spectra (Table 2) resembled those of verticilide $\mathrm{A} 1$. The ${ }^{13} \mathrm{C}$ NMR spectrum $\left(\mathrm{CDCl}_{3}\right)$ showed 43 resolved peaks (Table 2), which were classified into 11 methyl, 16 methylene, 8 methine and 8 carbonyl carbons by analysis of the DEPT spectrum. The connectivity of the proton and carbon atoms was confirmed by the HMQC spectrum (Table 2). As shown by bold lines in Figure 4, eight partial structures contained in the partial structure $\mathrm{V}$ were identified by ${ }^{1} \mathrm{H}-{ }^{1} \mathrm{H}$ COSY. The ${ }^{13} \mathrm{C}-{ }^{1} \mathrm{H}$ long-range couplings of ${ }^{2} J$ and ${ }^{3} J$ were measured in the HMBC spectrum (Figure $4 \mathrm{a}$ ), leading to the following results: (1) the cross peaks from $\mathrm{HA}-\alpha-\mathrm{H}(\delta$ 5.27) and HA- $\beta-\mathrm{H}(\delta$ 1.68) to HA-C $=\mathrm{O}(\delta$ 170.2), from MeAla- $\beta-\mathrm{H}(\delta 1.42)$ to MeAla- $\mathrm{C}=\mathrm{O}(\delta$ 171.8), from MeAla- $\alpha-\mathrm{H}(\delta$ 4.99) to MeAla- $\mathrm{C}=\mathrm{O}$ and $\mathrm{HA}-\mathrm{C}=\mathrm{O}$, and from MeAla-NMe-H $(\delta 3.07)$ to MeAla- $\alpha-\mathrm{C}\left(\delta\right.$ 51.8) and HA-C $=\mathrm{O}$ and the ${ }^{4} J$ cross peak from MeAla-NMe-H to HA- $\alpha-\mathrm{C}$ showed the presence of first 2-hydroxyheptanoyl- $\mathrm{N}$-methylalanine moiety (partial structure I); (2) the cross peaks from MeAla- $\beta-\mathrm{H}(\delta$ 1.52) to MeAla- $\mathrm{C}=\mathrm{O}(\delta$ 169.9), from MeAla-NMe-H $(\delta$ 3.19) to MeAla- $\alpha-\mathrm{C}(\delta$ 59.5) and HA-C $=\mathrm{O}$ $\left(\delta\right.$ 171.2) and the ${ }^{4} J$ cross peak from MeAla- $\alpha-\mathrm{H}(\delta$ 3.75) to HA- $\alpha-\mathrm{C}$ $(\delta 72.0)$ showed the presence of second 2-hydroxyheptanoyl- $N$-methylalanine moiety (partial structure II); (3) the cross peaks from HA- $\alpha-\mathrm{H}$ $(\delta$ 5.52) to HA-C $=\mathrm{O}(\delta 169.9)$, from MeAla- $\beta-\mathrm{H}(\delta 1.38)$ to MeAla$\mathrm{C}=\mathrm{O}(\delta$ 171.9), and from MeAla-NMe-H $(\delta$ 2.95) to MeAla- $\alpha-\mathrm{C}$ $\left(\delta\right.$ 52.1) and HA-C $=\mathrm{O}$ and the ${ }^{4} J$ cross peak from MeAla-NMe-H to HA$\alpha$-C showed the presence of third 2-hydroxyheptanoyl- $N$-methylalanine 
Table 1 Physico-chemical properties of verticilides A1, A2, A3 and B1

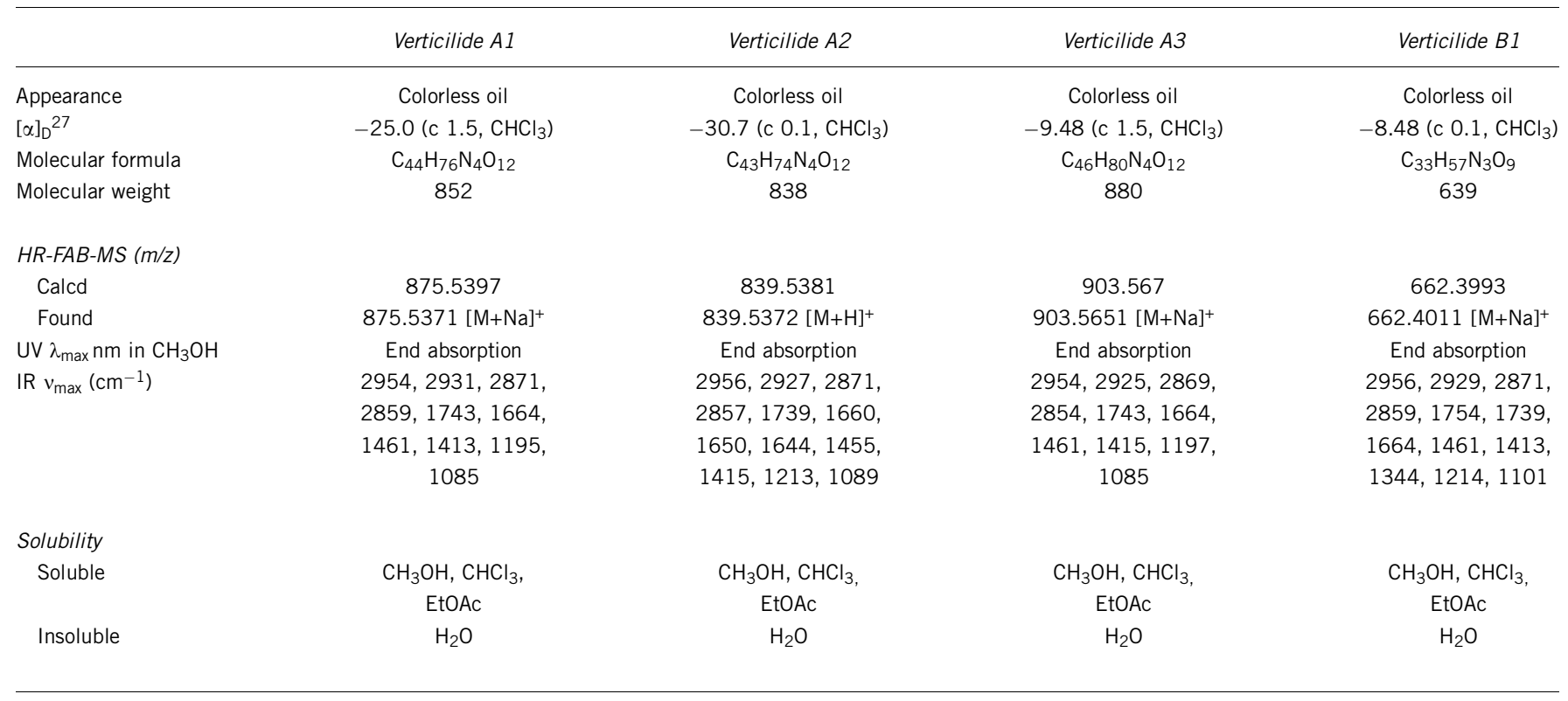

moiety (partial structure III); and (4) the cross peaks from Ala- $\beta-\mathrm{H}$ ( $\delta$ 1.39) to Ala- $\mathrm{C}=\mathrm{O}(\delta$ 171.9) showed the presence of the alanine moiety (partial structure IV). Furthermore, the long-range couplings from $\mathrm{HA}-\alpha-\mathrm{H}$ in the partial structure I to MeAla-C $=\mathrm{O}$ in the partial structure III, from $\mathrm{HA}-\alpha-\mathrm{H}$ in the partial structure III to Ala-C $=\mathrm{O}$ in the partial structure IV, from HA- $\alpha-\mathrm{H}$ in the partial structure V to MeAla$\mathrm{C}=\mathrm{O}$ in the partial structure II, and from $\mathrm{HA}-\alpha-\mathrm{H}$ in the partial structure II to MeAla- $\mathrm{C}=\mathrm{O}$ in the partial structure I showed the presence of linear octadepsipeptide moiety, as shown in Figure $4 \mathrm{~b}$. Considering the remaining atoms (one carbon and one oxygen), the existence of one carbonyl group was supported by its ${ }^{13} \mathrm{C}$ NMR chemical shift $(\delta$ 171.0). Therefore, it was concluded that the partial structure IV was connected to the partial structure V via an amide bond. From these observations, the structure of verticilide A2 was elucidated as $\mathrm{N}$-monodemethyl analog of verticilide A1 (Figure 1) and fulfilled the molecular formula.

Structure of verticilide A3. The molecular formula of verticilide A3 was determined to be $\mathrm{C}_{46} \mathrm{H}_{80} \mathrm{~N}_{4} \mathrm{O}_{12}$ on the basis of HR-FAB-MS measurement $\left(\mathrm{m} / \mathrm{z}\right.$ found 903.5651, calcd 903.5670 for $\mathrm{C}_{46} \mathrm{H}_{80}$ $\mathrm{N}_{4} \mathrm{O}_{12} \mathrm{Na}[\mathrm{M}+\mathrm{Na}]^{+}$), indicating that it was larger than verticilide $\mathrm{A} 1$ by two carbons and four protons, which corresponded to two methylenes from analysis of the DEPT spectra. The ${ }^{1} \mathrm{H}$ and ${ }^{13} \mathrm{C}$ NMR spectra observed in $\mathrm{CD}_{3} \mathrm{OD}$ with $1 \mathrm{mM}$ potassium thiocyanate (Table 2) resembled those of verticilide $\mathrm{A} 1$ observed in $\mathrm{CD}_{3} \mathrm{OD}$ with $300 \mathrm{~mm}$ potassium thiocyanate. From the detailed analysis of the ${ }^{1} \mathrm{H}$ ${ }^{1} \mathrm{H}$ COSY and the ${ }^{1} \mathrm{H}_{-}{ }^{13} \mathrm{C}$ HMBC experiments, verticilide $\mathrm{A} 3$ was found to be composed of 2-hydroxyheptanoyl- $N$-methylalanine and 2-hydroxynonanoyl- $N$-methylalanine moieties in a ratio of $3: 1$. Furthermore, fragment ion peaks were observed at $\mathrm{m} / \mathrm{z} 242,370$, 455, 583, 668, 796 and 881 in FAB-MS (Figure 5). From these observations, the structure of verticilide A3 was elucidated as shown in Figure 1 and fulfilled the molecular formula.

Structure of verticilide B1. The molecular formula of verticilide B1 was determined to be $\mathrm{C}_{33} \mathrm{H}_{57} \mathrm{~N}_{3} \mathrm{O}_{9}$ on the basis of HR-FAB-MS measurement $\left(\mathrm{m} / z\right.$ found 662.4011 , calcd 662.3993 for $\mathrm{C}_{33} \mathrm{H}_{57} \mathrm{~N}_{3}$
$\left.\mathrm{O}_{9} \mathrm{Na}[\mathrm{M}+\mathrm{Na}]^{+)}\right)$. The ${ }^{13} \mathrm{C}$ NMR spectrum $\left(\mathrm{CDCl}_{3}\right)$ showed 11 resolved peaks (Table 2), which were classified into three methyl, four methylene, two methine and two carbonyl carbons by analysis of the DEPT spectrum. The ${ }^{1} \mathrm{H}$ NMR spectrum in $\mathrm{CDCl}_{3}$ displayed nine proton signals (Table 2). These data suggested that verticilide B1 was a cyclic trimer composed of $\mathrm{C}_{11} \mathrm{H}_{19} \mathrm{NO}_{3}$ units. The connectivity of proton and carbon atoms was confirmed by the HMQC spectrum (Table 2). As shown by bold lines in Figure 6, the three partial structures were elucidated by ${ }^{1} \mathrm{H}-{ }^{1} \mathrm{H}$ COSY. The ${ }^{13} \mathrm{C}-{ }^{1} \mathrm{H}$ long-range couplings of ${ }^{2} \mathrm{~J}$ and ${ }^{3} \mathrm{~J}$ in the HMBC spectrum are also shown in Figure 6, leading to the following results: (1) the cross peaks from HA$\beta-\mathrm{H}(\delta$ 1.78) to HA- $\delta-\mathrm{C}(\delta 32.5)$, from HA- $\zeta-\mathrm{H}(\delta 0.92)$ to HA- $\delta-\mathrm{C}$, and from $\mathrm{HA}-\beta-\mathrm{H}$ to $\mathrm{HA}-\mathrm{C}=\mathrm{O}(\delta$ 167.5) showed the presence of a 2hydroxyheptanoic acid moiety; (2) The long-range couplings from MeAla-NMe-H $(\delta$ 3.08) to MeAla- $\alpha-\mathrm{C}(\delta$ 53.5), from MeAla- $\alpha-\mathrm{H}(\delta$ $5.06)$ to MeAla- $\mathrm{C}=\mathrm{O}(\delta 172.2)$, and from MeAla- $\beta-\mathrm{H}(\delta 1.42)$ to MeAla- $\mathrm{C}=\mathrm{O}$ showed the presence of an $N$-methylalanine moiety, supporting the result of amino-acid hydrolysis of verticilide B1. Thus, the $\mathrm{C}_{11} \mathrm{H}_{19} \mathrm{NO}_{3}$ units of verticilide $\mathrm{B} 1$ (partial structure I) was elucidated as shown in Figure 6. Furthermore, the long-range couplings from MeAla-NMe- $\mathrm{H}$ and MeAla- $\alpha-\mathrm{H}$ to $\mathrm{HA}-\mathrm{C}=\mathrm{O}$ showed that 2-hydroxypentanoic acid was attached to $N$-methylalanine via an amide bond. Therefore, verticilide B1 was a cyclic trimer constructed with partial structure I. From these observations, the structure of verticilide B1 was elucidated as shown in Figure 1 and fulfilled the molecular formula.

\section{Inhibition of cholesteryl ester (CE) synthesis in ACAT1- and ACAT2-CHO cells}

The effect of verticilides on ACAT1 and ACAT2 isozymes was evaluated in a cell-based assay using ACAT1- and ACAT2-CHO cells. As shown by the $\mathrm{IC}_{50}$ values summarized in Table 3 , all of the verticilides inhibited both ACAT1 and ACAT2; they showed, however, a degree of selective inhibition (more potent $\mathrm{IC}_{50} \mathrm{~s}$ ) towards ACAT2 compared with ACAT1, with selectivity index (SI) of 8.5-11. A number of synthetic ACAT inhibitors have been reported, but no 
Table $2{ }^{1} \mathrm{H}$ and ${ }^{13} \mathrm{C}$ NMR chemical shifts of verticilides $\mathrm{A2}, \mathrm{A} 3$ and $\mathrm{B} 1$

\begin{tabular}{|c|c|c|c|c|c|}
\hline & $\delta_{H}(p . p . m .)^{a}$ & $\delta_{C}(\text { p.p.m. })^{\mathrm{b}}$ & & $\delta_{H}(\text { p.p.m. })^{\mathrm{a}}$ & $\delta_{C}(p . p . m .)^{b}$ \\
\hline \multicolumn{6}{|l|}{ Verticilide $\mathrm{A} 2$ (in $\mathrm{CDCl}_{3}$ ) } \\
\hline (Unit I) & & & (Unit III) & & \\
\hline N-methylalanine (MeAla) & & & N-methylalanine (MeAla) & & \\
\hline $\mathrm{C}=\mathrm{O}$ & - & $171.8(\mathrm{~s})$ & $\mathrm{C}=\mathrm{O}$ & - & 171.9 (s) \\
\hline$\alpha$ & $4.99(1 \mathrm{H}, \mathrm{m})$ & $51.8(d)$ & $\alpha$ & $5.35(1 \mathrm{H}, \mathrm{m})$ & $52.1(\mathrm{~d})$ \\
\hline$\beta$ & $1.42(3 \mathrm{H}, \mathrm{d}, J=7.2)$ & $14.3(q)$ & $\beta$ & $1.38(3 \mathrm{H}, \mathrm{d}, J=7.2)$ & $14.5(q)$ \\
\hline $\mathrm{NCH}_{3}$ & $3.07(3 \mathrm{H}, \mathrm{s})$ & $30.3(q)$ & $\mathrm{NCH}_{3}$ & $2.95(3 \mathrm{H}, \mathrm{s})$ & $31.2(q)$ \\
\hline 2-Hydroxyheptanoic acid (HA) & & & 2-Hydroxyheptanoic acid (HA) & & \\
\hline $\mathrm{C}=\mathrm{O}$ & - & 170.2 (s) & $\mathrm{C}=\mathrm{O}$ & - & 169.9 (s) \\
\hline$\alpha$ & $5.27(1 \mathrm{H}, \mathrm{t}, \mathrm{J}=7.2)$ & 71.2 (d) & $\alpha$ & $5.52(1 \mathrm{H}, \mathrm{m})$ & 69.9 (d) \\
\hline$\beta$ & $1.68(2 \mathrm{H}, \mathrm{m})$ & $30.7(t)$ & $\beta$ & $1.82(2 \mathrm{H}, \mathrm{m})$ & $31.4(t)$ \\
\hline$\gamma$ & & & $\gamma$ & & \\
\hline$\delta\}$ & $1.20 \sim 1.50(2 \mathrm{H}, \mathrm{m})$ & $22.5 \sim 32.0^{c}(t)$ & $\delta\}$ & $1.20 \sim 1.50(2 \mathrm{H}, \mathrm{m})$ & $22.5 \sim 32.0^{c}(\mathrm{t})$ \\
\hline$\varepsilon J$ & & & $\varepsilon J$ & & \\
\hline$\zeta$ & $0.88(3 \mathrm{H}, \mathrm{m})$ & $13.9 \sim 14.4^{d}(q)$ & $\zeta$ & $0.88(3 \mathrm{H}, \mathrm{m})$ & $13.9 \sim 14.4^{d}(q)$ \\
\hline (Unit II) & & & (Unit IV) & & \\
\hline N-methylalanine (MeAla) & & & Alanine (Ala) & & \\
\hline $\mathrm{C}=\mathrm{O}$ & - & 169.9 (s) & $\mathrm{C}=\mathrm{O}$ & - & $171.9(\mathrm{~s})$ \\
\hline$\alpha$ & $3.75(1 \mathrm{H}, \mathrm{m})$ & $59.5(d)$ & $\alpha$ & $4.71(1 \mathrm{H}, \mathrm{t}, J=8.0)$ & $47.1(d)$ \\
\hline$\beta$ & $1.52(3 \mathrm{H}, \mathrm{d}, \mathrm{J}=7.2)$ & $13.5(q)$ & $\beta$ & $1.39(3 \mathrm{H}, \mathrm{d}, J=7.2)$ & $15.8(q)$ \\
\hline \multirow[t]{2}{*}{$\mathrm{NCH}_{3}$} & $3.19(3 \mathrm{H}, \mathrm{s})$ & $36.8(q)$ & $\mathrm{NH}$ & $7.45(3 \mathrm{H}, \mathrm{bs})$ & - \\
\hline & & & $($ Unit V) & & \\
\hline 2-Hydroxyheptanoic acid (HA) & & & 2-Hydroxyheptanoic acid (HA) & & \\
\hline $\mathrm{C}=\mathrm{O}$ & - & $171.2(\mathrm{~s})$ & $\mathrm{C}=\mathrm{O}$ & - & $170.0(\mathrm{~s})$ \\
\hline$\alpha$ & $5.00(1 \mathrm{H}, \mathrm{m})$ & $72.0(d)$ & $\alpha$ & $4.89(1 \mathrm{H}, \mathrm{m})$ & 75.9 (d) \\
\hline$\beta$ & $1.58(2 \mathrm{H}, \mathrm{m})$ & $24.8(t)$ & $\beta$ & $1.75(2 \mathrm{H}, \mathrm{m})$ & $31.0(t)$ \\
\hline$\gamma$ & & & $\gamma$ & & \\
\hline$\delta\}$ & $1.20 \sim 1.50(2 \mathrm{H}, \mathrm{m})$ & $22.5 \sim 32.0^{c}(t)$ & $\delta\}$ & $1.20 \sim 1.50(2 \mathrm{H}, \mathrm{m})$ & $22.5 \sim 32.0^{c}(\mathrm{t})$ \\
\hline$\varepsilon J$ & & & $\varepsilon)$ & & \\
\hline$\zeta$ & $0.88(3 \mathrm{H}, \mathrm{m})$ & $13.9 \sim 14.4^{d}(q)$ & $\zeta$ & $0.88(3 \mathrm{H}, \mathrm{m})$ & $13.9 \sim 14.4^{d}(q)$ \\
\hline \multicolumn{6}{|c|}{ Verticilide $\mathrm{A} 3$ (in $\mathrm{CD}_{3} \mathrm{OD}$ with $1 \mathrm{~mm} \mathrm{KSCN}$ ) } \\
\hline (Unit I) & & & (Unit II) & & \\
\hline N-methylalanine (MeAla) & & & N-methylalanine (MeAla) & & \\
\hline $\mathrm{C}=\mathrm{O}$ & - & $173.0(\mathrm{~s})$ & $\mathrm{C}=\mathrm{O}$ & - & $173.0(\mathrm{~s})$ \\
\hline$\alpha$ & $5.36(1 \mathrm{H}, \mathrm{br} . \mathrm{s})$ & $53.9(d)$ & $\alpha$ & $5.36(1 \mathrm{H}$, br.s $)$ & $53.9(d)$ \\
\hline$\beta$ & $1.48(3 \mathrm{H}, \mathrm{d}, J=7.2)$ & $14.6(q)$ & $\beta$ & $1.48(3 \mathrm{H}, \mathrm{d}, J=7.2)$ & $14.6(q)$ \\
\hline $\mathrm{NCH}_{3}$ & $3.07(3 \mathrm{H}, \mathrm{s})$ & $31.9(q)$ & $\mathrm{NCH}_{3}$ & $3.07(3 \mathrm{H}, \mathrm{s})$ & $31.9(q)$ \\
\hline 2-Hydroxyheptanoic acid (HA) & & & 2-Hydroxynonanoic acid (HA) & & \\
\hline $\mathrm{C}=\mathrm{O}$ & - & $172.3(\mathrm{~s})$ & $\mathrm{C}=\mathrm{O}$ & - & $172.3(\mathrm{~s})$ \\
\hline$\alpha$ & $5.30(1 \mathrm{H}, \mathrm{t}, \mathrm{J}=6.4)$ & 73.8 (d) & $\alpha$ & $5.30(1 \mathrm{H}, \mathrm{t}, \mathrm{J}=6.4)$ & $73.8(d)$ \\
\hline$\beta$ & $1.82(2 \mathrm{H}, \mathrm{m})$ & $31.5(\mathrm{t})$ & $\beta$ & $1.82(2 \mathrm{H}, \mathrm{m})$ & $31.5(\mathrm{t})$ \\
\hline$\gamma$ & $1.52(2 \mathrm{H}, \mathrm{m})$ & $25.8(t)$ & $\gamma$ & $1.52(2 \mathrm{H}, \mathrm{m})$ & $26.1(\mathrm{t})$ \\
\hline$\delta$ & $1.38(2 \mathrm{H}, \mathrm{m})$ & $32.5(t)$ & $\delta\}$ & $1.36(2 \mathrm{H})$ & $30.1,30.2(t)$ \\
\hline$\varepsilon$ & $1.38(2 \mathrm{H}, \mathrm{m})$ & $23.4(t)$ & $\varepsilon \quad$ & & \\
\hline \multirow[t]{3}{*}{$\zeta$} & $0.94(3 \mathrm{H}, \mathrm{m})$ & $14.2(q)$ & $\zeta$ & $1.38(2 \mathrm{H}, \mathrm{m})$ & $32.8(t)$ \\
\hline & & & $\eta$ & $1.38(2 \mathrm{H}, \mathrm{m})$ & $23.6(t)$ \\
\hline & & & $\theta$ & $0.94(3 \mathrm{H}, \mathrm{m})$ & $14.4(q)$ \\
\hline
\end{tabular}

Verticilide $\mathrm{B} 1$ (in $\mathrm{CDCl}_{3}$ )

$\mathrm{N}$-methylalanine (MeAla)

$\begin{array}{lcc}\mathrm{C}=\mathrm{O} & - & 172.2(\mathrm{~s}) \\ \alpha & 5.06(1 \mathrm{H}, \mathrm{q}, \mathrm{J}=7.6) & 53.5(\mathrm{~d}) \\ \beta & 1.42(3 \mathrm{H}, \mathrm{d}, \mathrm{J}=7.2) & 14.5(\mathrm{q}) \\ \mathrm{NCH}_{3} & 3.08(3 \mathrm{H}, \mathrm{s}) & 31.5(\mathrm{q})\end{array}$


Table 2 (Continued)

\begin{tabular}{|c|c|c|c|c|}
\hline & $\delta_{H}(p . p . m .)^{a}$ & $\delta_{C}(p . p . m .)^{b}$ & $\delta_{H}(p . p . m .)^{a}$ & $\delta_{C}(p . p . m .)^{b}$ \\
\hline \multicolumn{5}{|c|}{ 2-Hydroxyheptanoic acid (HA) } \\
\hline $\mathrm{C}=\mathrm{O}$ & - & $167.5(\mathrm{~s})$ & & \\
\hline$\beta$ & $1.78(2 \mathrm{H}, \mathrm{m})$ & $31.8(\mathrm{t})$ & & \\
\hline$\gamma$ & $1.34 \sim 1.50(2 \mathrm{H}, \mathrm{m})$ & $26.0(\mathrm{t})$ & & \\
\hline$\delta$ & $1.34(2 \mathrm{H}, \mathrm{m})$ & $32.5(\mathrm{t})$ & & \\
\hline
\end{tabular}

aspectra taken at $400 \mathrm{MHz}$.

bS Spectra taken at $100 \mathrm{MHz}$

c22.4, 22.4, 24.8, 25.3, 29.5, 29.7, 30.4, 31.0, 31.3, 31.3, 32.0, 34.0 p.p.m.

${ }^{d} 13.9,14.0,14.1,14.4$ p.p.m.

a I

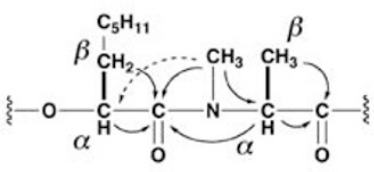

III

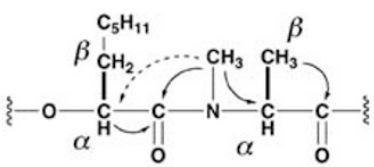

IV

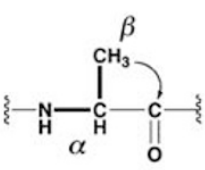

V

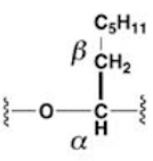

$-{ }^{1} \mathrm{H}-{ }^{1} \mathrm{H} \cos Y$

$\frown \operatorname{HMBC}\left({ }^{3} \mathrm{~J}\right)$

$\therefore$ HMBC $\left({ }^{4} \Omega\right.$

b

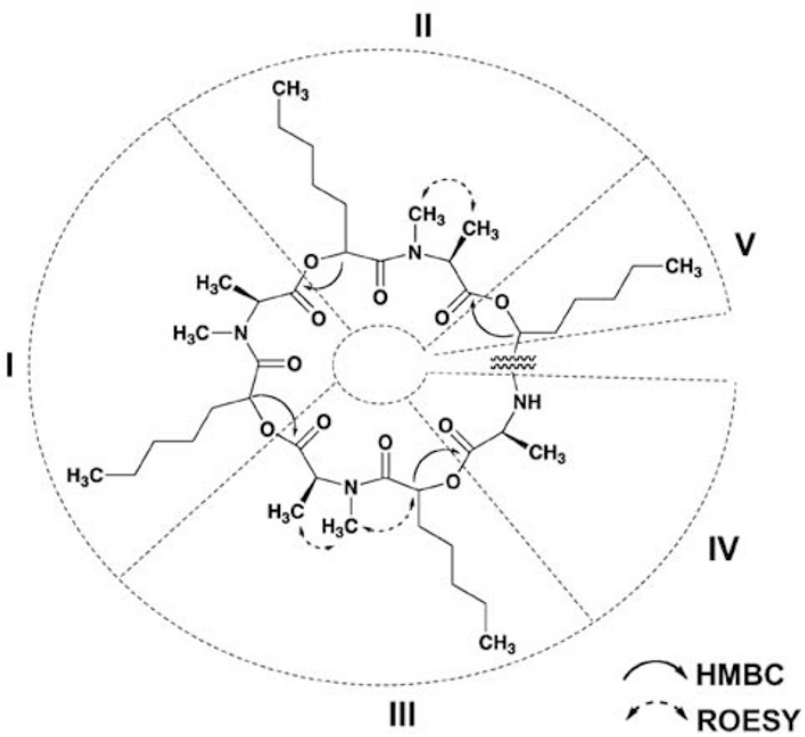

Figure 4 Partial structures $\mathrm{I}$ to $\mathrm{V}$ (a) and ${ }^{13} \mathrm{C}-{ }^{1} \mathrm{H}$ HMBC and ROESY experiments (b) of verticilide A2.

inhibitors have been clinically developed to date. Recently, attempts to use pactimibe ${ }^{29}$ and avasimibe, ${ }^{30,31}$ which were reported to inhibit both ACAT1 and ACAT2, clinically failed. On the other hand, our research group has been interested in ACAT2-selective inhibitors such

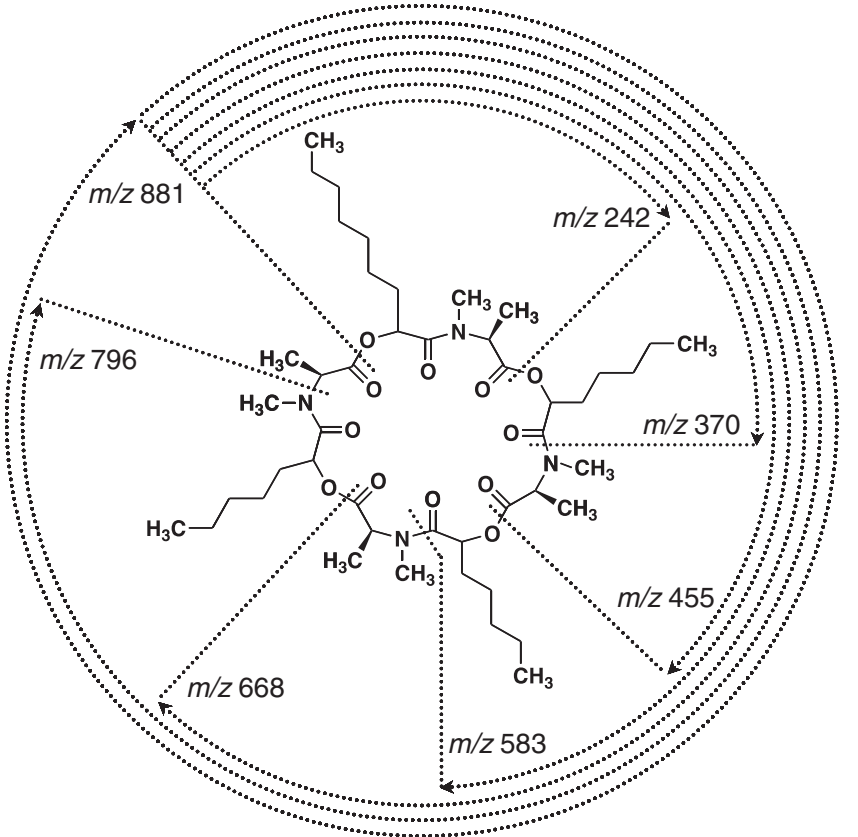

Figure 5 Mass fragments analysis of verticilide $A 3$ observed from FAB mass spectrum.

as the pyripyropenes as a different approach for the development of new anti-atherosclerotic agents. ${ }^{32}$ In this sense, verticilides might represent potential leads beyond the pyripyropenes, although their ACAT2 selectivity is insufficient. We previously reported that two types of depsipeptides, beauveriolides and beauvericin, had ACAT inhibitory activity ${ }^{25,33}$ and investigated their selectivity toward the two isozymes. Beauveriolides I and III were more selective toward ACAT1, while beauvericin inhibited both ACAT1 and ACAT2. ${ }^{15}$ Thus, these depsipeptides including the verticilides showed ACAT inhibitory properties but their isozyme selectivity appears diverse.

\section{Other biological activities}

Verticilide A1 was reported to inhibit the binding between ryanodine (insecticidal plant alkaloid) and cockroach ryanodine receptor with an $\mathrm{IC}_{50}$ value of $4.2 \mu \mathrm{m}^{20,21}$ Verticilides A2, A3 and B1 did not, however, inhibit this binding event at concentrations up to $100 \mu \mathrm{M}$. Verticilide B1 had the broad antimicrobial activity; active against Bacillus subtilis, 
I

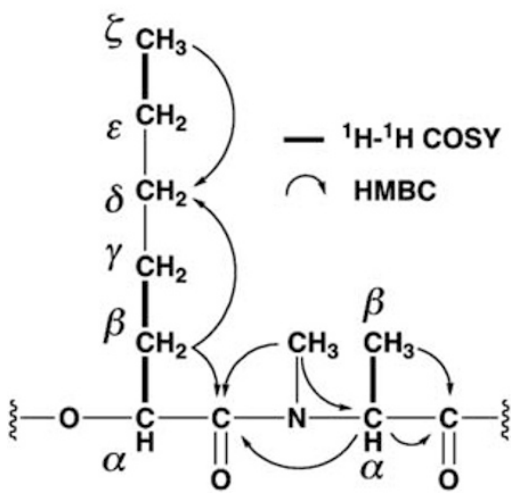

Figure 6 Partial structure I of verticilide B1.

Table 3 Effect of verticilides on ACAT1 and ACAT2 activity in ACAT1- and ACAT-2-CHO cells

\begin{tabular}{lccc} 
& \multicolumn{2}{c}{$\mathcal{C}_{50}(\mu \mathrm{m})$} & \\
\cline { 2 - 3 } Verticilide & ACAT1 & ACAT2 & $S^{\text {a }}$ \\
\hline A1 & 2.5 & 0.23 & 11 \\
A2 & 4.8 & 0.55 & 8.7 \\
A3 & 3.5 & 0.36 & 9.7 \\
B1 & 11 & 1.3 & 8.5
\end{tabular}

aSelectivity index (SI); I $\mathrm{C}_{50}$ for ACAT1/IC $\mathrm{C}_{50}$ for ACAT2.

Staphylococcus aureus, Micrococcus luteus, Pseudomonas aeruginosa and Mucor racemosus. On the other hand, verticilides A1 and A2 had limited antimicrobial activity; active against $P$. aeruginosa and $M$. racemosus, and against $P$. aeruginosa, respectively. Verticilide A3 showed no antimicrobial activity. Verticilides A1, A3 and B1 also showed moderate nematocidal activity against Artemia salina (data not shown).

\section{METHODS}

\section{General experimental procedures}

Fungal strain FKI-2679 was originally isolated from a soil sample collected on Ishigaki Island, Okinawa, Japan. This strain was used for the production of verticilides A1, A2, A3 and B1. Kieselgel 60 (Merck KGaA, Darmstadt, Germany) was used for silica gel column chromatography. To determine the amounts of verticilides A1, A2, A3 and B1 in culture broths, samples (ethyl acetate extracts) dissolved in methanol were analyzed using a HP1100 system (Hewlett-Packard Company, Palo Alto, CA, USA) under the following conditions: column, symmetry $(2.1 \times 150 \mathrm{~mm}$; Waters Corporation, Milford, MA, USA); flow rate, $0.2 \mathrm{ml} \mathrm{min}^{-1}$; mobile phase, a 20 -min linear gradient from $60 \%$ aqueous $\mathrm{MeCN}$ to $100 \% \mathrm{MeCN}$ containing $0.05 \% \mathrm{H}_{3} \mathrm{PO}_{4}$; detection, UV at $210 \mathrm{~nm}$.

UV spectra were recorded on a spectrophotometer (8453 UV-Visible spectrophotometer; Agilent Technologies Inc., Santa Clara, CA, USA). IR spectra were recorded on a Fourier transform infrared spectrometer (FT-710; Horiba Ltd., Kyoto, Japan). Optical rotations were measured with a digital polarimeter (DIP-1000; JASCO Co., Tokyo, Japan). FAB-MS spectra were recorded on a mass spectrometer (JMS-DX300; JEOL Ltd., Tokyo, Japan). Various NMR spectra were measured with a spectrometer (XL-400; Varian Inc., Palo Alto, CA, USA).

Taxonomic studies of the producing strain FKI-2679

Fungal strain FKI-2679 was isolated from soil collected on Ishigaki Island, Okinawa, Japan. For determination of the morphological characteristics, the isolate was inoculated as a 1-point culture on PDA, MEA, LcA and PCA, and grown for 7 days at $25^{\circ} \mathrm{C}$ (also at 5 and $37^{\circ} \mathrm{C}$ on PDA) in the dark. Color Harmony Manual fourth Edition (Container Corporation of America, Chicago, IL, USA) was used to determine color names and hue numbers. ${ }^{34}$ For the determination of micro-morphological characteristics, the samples were observed under a Vanox-S AH-2 microscope (Olympus, Tokyo, Japan) and JSM-5600 scanning electron microscope (JEOL, Tokyo, Japan). The D1/D2 rDNA sequence of the strain was deposited at the DDBJ with accession number AB540177.

\section{Fermentation}

A slant culture of strain FKI-2679 grown on LCA (glycerol $0.10 \%, \mathrm{KH}_{2} \mathrm{PO}_{4}$ $0.080 \%, \mathrm{~K}_{2} \mathrm{HPO}_{4} 0.020 \%, \mathrm{MgSO}_{4} \cdot 7 \mathrm{H}_{2} \mathrm{O} 0.020 \%, \mathrm{KCl} 0.020 \%, \mathrm{NaNO}_{3} 0.20 \%$, yeast extract $0.020 \%$, agar $1.5 \%, \mathrm{pH} 6.0$ ) was inoculated into a $50-\mathrm{ml}$ tube containing $10 \mathrm{ml}$ seed medium (glucose $2.0 \%$, polypeptone $0.50 \%, \mathrm{MgSO}_{4}$. $7 \mathrm{H}_{2} \mathrm{O} 0.050 \%$, yeast extract $0.20 \%, \mathrm{KH}_{2} \mathrm{PO}_{4} 0.10 \%$, agar $0.10 \%$, $\mathrm{pH} 6.0$ ). The tube was shaken on a reciprocal shaker for 2 days at $27^{\circ} \mathrm{C}$. A 1-ml portion of the seed culture was then inoculated into a 500-ml Erlenmeyer flask containing the production medium (50 g Italian rice; Japan Europe Trading Co. Ltd., Tokyo, Japan). Fermentation was carried out at $27^{\circ} \mathrm{C}$ for 6 days under stable conditions.

\section{Acid hydrolysis}

Verticilides A2, A3 and B1 (100 $\mu$ g each) were degraded in the gas phase of $6 \mathrm{~N}$ $\mathrm{HC} 1(200 \mu \mathrm{l})$ at $110^{\circ} \mathrm{C}$ for $24 \mathrm{~h}$ using the PICO.TAG work station (Waters Corporation). ${ }^{20}$ To determine the stereochemistry of alanine and $\mathrm{N}$-methyl-Lalanine, the degradation products were dissolved in $\mathrm{MeOH}(100 \mu \mathrm{l})$ and separated on an HPTLC plate (chiral plate, CHIR; Merck, Darmstadt, Germany) with the solvent system $0.05 \mathrm{M} \mathrm{KH}_{2} \mathrm{PO}_{4} / \mathrm{MeOH} / \mathrm{MeCN}=5: 5: 1$ and amino acids were detected by ninhydrin reagent.

\section{Cell culture}

Two cell lines, CHO cells expressing ACAT1 and ACAT2 isozymes of African green monkey (ACAT1- and ACAT2-CHO cells, respectively) ${ }^{14}$ were kind gifts from Dr LL Rudel (Wake Forest University, Winston Salem, NC, USA). Cells were maintained as described previously. ${ }^{15}$

\section{Assay for ACAT1 and ACAT2 activities using ACAT1- and ACAT2-CHO cells}

Assays for ACAT1 and ACAT2 activities using ACAT1- and ACAT2-CHO cells were carried out by our established method. ${ }^{15}$ Briefly, ACAT1- or ACAT2-CHO cells $\left(1.25 \times 10^{5}\right.$ cells in $250 \mu \mathrm{l}$ of medium) were cultured in a 48 -well plastic microplate in the culture medium described above and allowed to recover overnight at $37^{\circ} \mathrm{C}$ in $5 \% \mathrm{CO}_{2}$. The assays were done with cells that were at least $80 \%$ confluent. Following the overnight recovery, test sample $(2.5 \mu \mathrm{l} \mathrm{MeOH}$ solution) and $\left[1-{ }^{14} \mathrm{C}\right]$ oleic acid $(5 \mu \mathrm{l} 10 \% \mathrm{EtOH} / \mathrm{PBS}$ solution, $1 \mathrm{nmol}$, $1.85 \mathrm{kBq}$ ) were added to each culture. After a 6-h incubation at $37^{\circ} \mathrm{C}$ in $5 \% \mathrm{CO}_{2}$, the medium was removed and the cells in each well were washed twice with PBS. The cells were lysed by adding $0.25 \mathrm{ml}$ of $10 \mathrm{~mm}$ Tris- $\mathrm{HCl}(\mathrm{pH} 7.5)$ containing $0.1 \%(\mathrm{w} / \mathrm{v})$ sodium dodecyl sulfate and $\left[{ }^{14} \mathrm{C}\right] \mathrm{CE}$ was analyzed with a BAS2000 analyzer (Fuji Film, Tokyo, Japan). In this cell-based assay, $\left[{ }^{14} \mathrm{C}\right] \mathrm{CE}$ was produced by the reaction of ACAT1 or ACAT2. ACAT inhibitory activity (\%) is defined as $\left(1-\left[{ }^{14} \mathrm{C}\right] \mathrm{CE}-\mathrm{drug} /\left[{ }^{14} \mathrm{C}\right] \mathrm{CE}\right.$-control $) \times 100$. The $\mathrm{IC}_{50}$ value is defined as the drug concentration causing $50 \%$ inhibition of a biological activity.

\section{Other biological assays}

Antimicrobial activity against 14 species of microorganisms was measured by a paper disk method. Media for growth of microorganisms were as follows: GAM agar (Nissui Seiyaku Co., Tokyo, Japan) for Bacteroides fragilis; Waksman agar for Mycobacterium smegmatis; Bacto PPLO agar (Difco) supplemented with $15 \%$ horse serum, $0.1 \%$ glucose, $0.2 \%$ phenol red $\left(5 \mathrm{mg} \mathrm{ml}^{-1}\right)$ and $1.5 \%$ agar for Acholeplasma laidlawii; nutrient agar for B. subtilis, S. aureus, M. luteus, Escherichia coli, P. aeruginosa and Xanthomonas oryzae; a medium composed of $1.0 \%$ glucose, $0.5 \%$ yeast extract and $0.8 \%$ agar for Pyricularia oryzae, Aspergillus niger, 
M. racemosus, Candida albicans and Saccharomyces cerevisiae. A paper disk (i.d. $6 \mathrm{~mm}$, Advantic) containing $10 \mu \mathrm{g}$ of a sample was placed on the agar plate. Bacteria except X. oryzae were incubated at $37^{\circ} \mathrm{C}$ for $24 \mathrm{~h}$. Yeasts and $X$. oryzae were incubated at $27^{\circ} \mathrm{C}$ for $24 \mathrm{~h}$. Fungi were incubated at $27^{\circ} \mathrm{C}$ for $48 \mathrm{~h}$. The insecticidal assay used Artemia salina as test organism. Briey, about 10 nuclei larvae hatched from eggs of A. salina in the culture medium $(295 \mu \mathrm{l}$, $0.24 \%$ Tris, $2.57 \% \mathrm{NaCl}, 0.47 \% \mathrm{MgCl}_{2}, 0.07 \% \mathrm{KCl}, 0.02 \% \mathrm{Na}_{2} \mathrm{CO}_{3}, 0.64 \%$ $\mathrm{MgSO}_{4}$ and $\left.0.11 \% \mathrm{CaCl}_{2}, \mathrm{pH} 7.0\right)$ were incubated with a sample $(5 \mu \mathrm{l} \mathrm{MeOH}$ solution) in a well of a 96 -well microplate at $20^{\circ} \mathrm{C}$. After $48 \mathrm{~h}$, the motility of $A$. salina was assessed visually and compared with the control (no test sample).

\section{ACKNOWLEDGEMENTS}

We are grateful to Dr LL Rudel (Wake Forest University, Winston Salem, NC, USA) for kindly providing ACAT1-CHO and ACAT2-CHO cells, Dr M Iwatsuki (Kitasato Institute for Life Sciences) for excellent assistance, Ms N Sato for measuring NMR experiments, and Ms A Nakagawa for measuring mass spectra. This work was supported by a grant-in-aid for Scientific Research (B) 18390008 (to HT) and Young Scientists (start-up) 20810028 (to DM) from the Ministry of Education, Culture, Sports, Science and Technology, Japan, and by the Kitasato University Research Grant for Young Researchers (to DM).

1 Sliskovic, D. R., Picard, J. A. \& Krause, B. R. ACAT inhibitors: the search for a novel and effective treatment of hypercholesterolemia and atherosclerosis. Prog. Med. Chem. 39, 121-171 (2002)

2 Alegret, M., Llaverias, G. \& Silvestre, J. S. Acyl coenzyme A:cholesterol acyltransferase inhibitors as hypolipidemic and antiatherosclerotic drugs. Methods Find. Exp. Clin. Pharmacol. 26, 563-586 (2004).

3 Miyazaki, A., Kanome, T. \& Watanabe, T. Inhibitors of acyl-coenzyme A: cholesterol acyltransferase. Curr. Drug Targets Cardiovasc. Haematol. Disord. 5, 463-469 (2005).

4 Chang, C. C., Huh, H. Y., Cadigan, K. M. \& Chang, T. Y. Molecular cloning and functional expression of human acyl-coenzyme A:cholesterol acyltransferase cDNA in mutant Chinese hamster ovary cells. J. Biol. Chem. 268, 20747-20755 (1993).

5 Anderson, R. A. et al. Identification of a form of acyl-CoA:cholesterol acyltransferase specific to liver and intestine in nonhuman primates. J. Biol. Chem. 273, $26747-$ 26754 (1998).

6 Cases, S. et al. ACAT-2, a second mammalian acyl-CoA:cholesterol acyltransferase. Its cloning, expression, and characterization. J. Biol. Chem. 273, 26755-26764 (1998).

7 Oelkers, P., Behari, A., Cromley, D., Billheimer, J. T. \& Sturley, S. L. Characterization of two human genes encoding acyl coenzyme A:cholesterol acyltransferase-related enzymes. J. Biol. Chem. 273, 26765-26771 (1998).

8 Parini, P. et al. ACAT2 is localized to hepatocytes and is the major cholesterolesterifying enzyme in human liver. Circulation 110, 2017-2023 (2004).

9 Yagyu, H. et al. Absence of ACAT-1 attenuates atherosclerosis but causes dry eye and cutaneous xanthomatosis in mice with congenital hyperlipidemia. J. Biol. Chem. 275, 21324-21330 (2000).

10 Accad, M. et al. Massive xanthomatosis and altered composition of atherosclerotic lesions in hyperlipidemic mice lacking acyl CoA:cholesterol acyltransferase 1. J. Clin. Invest. 105, 711-719 (2000).

11 Fazio, S. et al. Increased atherosclerosis in LDL receptor-null mice lacking ACAT1 in macrophages. J. Clin. Invest. 107, 163-171 (2001).
12 Buhman, K. K. et al. Resistance to diet-induced hypercholesterolemia and gallstone formation in ACAT2-deficient mice. Nat. Med. 6, 1341-1347 (2000).

13 Willner, E. L. et al. Deficiency of acyl CoA:cholesterol acyltransferase 2 prevents atherosclerosis in apolipoprotein E-deficient mice. Proc. Natl Acad. Sci. USA 100, 1262-1267 (2003).

14 Lada, A. T. et al. Identification of ACAT1- and ACAT2-specific inhibitors using a novel, cell-based fluorescence assay: individual ACAT uniqueness. J. Lipid Res. 45, 378-386 (2004).

15 Ohshiro, T., Rudel, L. L., Omura, S. \& Tomoda, H. Selectivity of microbial acyl-CoA: cholesterol acyltransferase inhibitors toward isozymes. J. Antibiot. 60, 43-51 (2007).

16 Ikenoya, M. et al. A selective ACAT-1 inhibitor, K-604, suppresses fatty streak lesions in fat-fed hamsters without affecting plasma cholesterol levels. Atherosclerosis 191, 290-297 (2007).

17 Tomoda, H. \& Omura, S. Potential therapeutics for obesity and atherosclerosis: inhibitors of neutral lipid metabolism from microorganisms. Pharmacol. Ther. 115, 375-389 (2007).

18 Sakai, K. et al. Selective inhibition of acyl-CoA:cholesterol acyltransferase 2 isozyme by flavasperone and sterigmatocystin from Aspergillus species. J. Antibiot. 61, 568-572 (2008).

19 Ohshiro, T. \& Tomoda, H. Isoform-specific inhibitors of ACATs: recent advances and promising developments. Future Med. Chem. 3, 2039-2061 (2011).

20 Monma, S. et al. Verticilide: elucidation of absolute configuration and total synthesis. Org. Lett. 8, 5601-5604 (2006).

21 Shiomi, K. et al. Verticilide, a new ryanodine-binding inhibitor, produced by Verticillium sp. FKI-1033. J. Antibiot. 63, 77-82 (2010).

22 Namatame, I., Tomoda, H., Si, S., Yamaguchi, Y., Masuma, R. \& Omura, S. Beauveriolides, specific inhibitors of lipid droplet formation in mouse macrophages, produced by Beauveria sp. FO-6979. J. Antibiot. 52, 1-6 (1999).

23 Namatame, I., Tomoda, H., Tabata, N., Si, S. \& Omura, S. Structure elucidation of fungal beauveriolide III, a novel inhibitor of lipid droplet formation in mouse macrophages. J. Antibiot. 52, 7-12 (1999).

24 Matsuda, D. et al. New beauveriolides produced by amino acid-supplemented fermentation of Beauveria sp. FO-6979. J. Antibiot. 57, 1-9 (2004).

25 Tomoda, H. et al. Inhibition of acyl-CoA: cholesterol acyltransferase activity by cyclodepsipeptide antibiotics. J. Antibiot. 45, 1626-1632 (1992).

26 Tomoda, H. et al. New cyclodepsipeptides, enniatins D, E and F produced by Fusarium sp. FO-1305. J. Antibiot. 45, 1207-1215 (1992).

27 Kanaoka, M., Isogai, A. \& Suzuki, A. Bassianolide, a new insecticidal cyclodepsipeptide from Beauveria bassiana and Verticillium lecanii. Agric. Biol. Chem. 43, 629-635 (1979).

28 von Arx, J. A. The Genera of Fungi Sporulating in Pure Culture, 3rd edn. (Verlag J Cramer: Vaduz, 1981).

29 Tardif, J. C. et al. Effects of the acyl coenzyme A:cholesterol acyltransferase inhibitor avasimibe on human atherosclerotic lesions. Circulation 110, 3372-3377 (2004).

30 Nissen, S. E. et al. Effect of ACAT inhibition on the progression of coronary atherosclerosis. N. Engl. J. Med. 354, 1253-1263 (2006).

31 Meuwese, M. C. et al. ACAT inhibition and progression of carotid atherosclerosis in patients with familial hypercholesterolemia: the CAPTIVATE randomized trial. JAMA 301, 1131-1139 (2009).

32 Ohshiro, T. et al. Pyripyropene A, an acyl-coenzyme A:cholesterol acyltransferase 2-selective inhibitor, attenuates hypercholesterolemia and atherosclerosis in murine models of hyperlipidemia. Arterioscler. Thromb. Vasc. Biol. 31, 1108-1115 (2011).

33 Namatame, I., Tomoda, H., Ishibashi, S. \& Omura, S. Antiatherogenic activity of fungal beauveriolides, inhibitors of lipid droplet accumulation in macrophages. Proc. Natl Acad. Sci. USA 101, 737-742 (2004).

34 Jacobson, E., Granville, W. C. \& Foss, C. E. Color Harmony Manual. 4th edn Container of America: Chicago, USA, (1958). 